\title{
Identification of microRNA-487b as a negative regulator of liver metastasis by regulation of KRAS in colorectal cancer
}

\author{
TSUYOSHI HATA ${ }^{1}$, YUKAKO MOKUTANI ${ }^{2}$, HIDEKAZU TAKAHASHI ${ }^{1}$, AKIRA INOUE ${ }^{1}$, \\ KOJI MUNAKATA ${ }^{1}$, KAZUYA NAGATA ${ }^{3}$, NAOTSUGU HARAGUCHI ${ }^{1}$, JUNICHI NISHIMURA $^{1}$, \\ TAISHI HATA ${ }^{1}$, CHU MATSUDA $^{1}$, KOHEI MURATA ${ }^{4}$, TSUNEKAZU MIZUSHIMA ${ }^{1}$, \\ YUICHIRO DOKI $^{1}$, MASAKI MORI $^{1}$ and HIROFUMI YAMAMOTO ${ }^{1,3}$
}

\author{
${ }^{1}$ Department of Surgery, Gastroenterological Surgery, Graduate School of Medicine, Osaka University, Suita, Osaka 565-0871; \\ ${ }^{2}$ Department of Surgery, Yao Municipal Hospital, Yao, Osaka 581-0069; ${ }^{3}$ Department of Molecular Pathology, \\ Division of Health Sciences, Graduate School of Medicine, Osaka University, Suita, Osaka 565-0871; \\ ${ }^{4}$ Department of Surgery, Suita Municipal Hospital, Suita, Osaka 564-0082, Japan
}

Received July 7, 2016; Accepted October 20, 2016

DOI: 10.3892/ijo.2016.3813

\begin{abstract}
Recent studies have shown that microRNAs (miRNAs) are involved in the progression of colorectal cancer (CRC). The aim of this study is to identify a novel miRNA that especially relates to liver metastasis and to explore the underlying mechanism. Differentially expressed miRNAs were analyzed using microarray, in primary CRC tumors without metastasis $(n=16)$, those with liver metastasis $(n=12)$, and liver metastatic lesions $(n=8)$. We found that miR-487b level decreased in liver metastatic lesions, and qRT-PCR confirmed the results in the validating cohort $(n=134)$. Survival analysis indicated that high expression of $\mathrm{miR}-487 \mathrm{~b}$ was associated with better prognosis. In vitro studies were also performed to investigate the functional significance of miR-487b in human CRC cell lines. miR-487b showed an inhibitory effect on cell proliferation and invasion of CRC cells. miR-487b downregulated KRAS and inhibited its downstream signal pathways, and the luciferase reporter assay revealed that miR-487b directly targeted LRP6, a receptor for WNT/ $\beta$-catenin signaling. These findings showed that decrease in $\mathrm{miR}-487 \mathrm{~b}$ was related with liver metastasis. Our data suggest a possibility that miR-487b may suppress metastasis of CRC progression through inhibition of KRAS.
\end{abstract}

\section{Introduction}

Colorectal cancer (CRC) is the third most common cancer and the fourth most common cancer cause of death globally

Correspondence to: Dr Hirofumi Yamamoto, Department of Surgery, Gastroenterological Surgery, Graduate School of Medicine, Osaka University, 2-2, Yamadaoka, Suita, Osaka 565-0871, Japan

E-mail: hyamamoto@gesurg.med.osaka-u.ac.jp

Key words: miR-487b, colorectal cancer, liver metastasis, KRAS, LRP6 with $\sim 1.2$ million new cases and 600,000 deaths per year $(1,2)$. Metastatic diseases occur in $\sim 30-50 \%$ of CRC patients, either at the time of initial diagnosis or during follow-up $(3,4)$. CRC metastasizes predominantly to the liver, and liver metastases account for at least two thirds of CRC deaths $(3,5,6)$. Despite advances in research on primary CRC development, the mechanism for the progression from local disease to metastasis is not fully understood. Therefore, it is highly required to identify sensitive biological markers for early detection and the risk of metastasis in CRC.

MicroRNA (miRNA) is a small non-coding RNA of 20-24 base in length, and it post-transcriptionally regulates the expression of multiple target genes by binding to complementary sequences, mainly in the 3'-untranslated regions (3'-UTR) of the genes $(7,8)$. miRNA also plays a crucial role in cancer, and its aberrant expression may cause uncontrolled cell proliferation, invasion, and metastasis (9-12). Many miRNAs involved in development and progression of CRC have been identified, and some of them are reportedly shown to have potential value as biomarkers for diagnosis, prognosis and susceptibility in CRC $(13,14)$. Recently, a few miRNAs are being tested for the clinical practice. For instance, a phase I trial with miRNA-34 is currently ongoing to evaluate its safety (15). However, further studies are needed to comprehend the whole biological systems of miRNAs in CRC.

We previously performed microarray analyses to explore miRNAs that showed differential expression among primary CRC tumors with or without liver metastasis, and liver metastatic lesions. We reported that miRNA-132 was downregulated in the liver metastasis-related samples, and that this miRNA was associated with better prognosis in CRC (16). In this study, we aimed at identifying another novel miRNA that was aberrantly expressed in liver metastasis, using the microarray data. We found that miRNA-487b (miR-487b) decreased in CRC tumors with liver metastasis and liver metastatic lesions when compared with CRC tumors without metastasis. Studies show that miR-487b inhibits $\mathrm{WNT} / \beta$-catenin signaling pathway and suppresses metastasis in lung cancer $(17,18)$. Xi et al also 
reported that KRAS was a direct target of miR-487b in lung cancer (17). Furthermore, Gattolliat et al showed that miR$487 \mathrm{~b}$ could be a favorable prognostic marker in neuroblastoma (19). These findings suggest a possibility that miR-487b functions as a tumor suppressor. However, to our knowledge, no studies have examined miR-487b expression in CRC. The aim of this study was to reveal the clinical significance of miR$487 \mathrm{~b}$ in $\mathrm{CRC}$.

\section{Materials and methods}

Collection of human tissue specimens. Tumor tissues were collected from 134 patients who received surgery between 2003 and 2013 at Osaka University Hospital and its three related facilities: 96 primary CRC tumors with stage I $(\mathrm{n}=18)$, II $(\mathrm{n}=38)$, and III $(\mathrm{n}=40)$ disease without metastasis, 22 primary CRC tumors with simultaneous liver metastasis (stage IV), and 16 liver metastatic lesions of CRC. All samples were immediately frozen in RNAlater (Ambion, Austin, TX, USA) and stored at $-80^{\circ} \mathrm{C}$ until RNA extraction. This study was approved by the institutional review board of each institution, and all subjects provided written informed consents before participation. The clinical parameters of the validating cohort are shown in Table I.

Cell lines and culture. Human CRC cell lines DLD-1 (KRAS G13D), HCT116 (KRAS G13D), HT29 (BRAF V600E), and SW480 (KRAS G12V) were purchased from the American Type Culture Collection (Rockville, MD, USA) in 2001. Cell lines were maintained in Dulbecco's modified Eagle's medium (Sigma-Aldrich, St. Louis, MO, USA) with $10 \%$ fetal bovine serum in a humidified $5 \% \mathrm{CO}_{2}$ at $37^{\circ} \mathrm{C}$.

Transient oligonucleotide transfection. miR-487b and negative control miRNA were purchased from Gene Design Inc. (Osaka, Japan). These were transfected into cells $24 \mathrm{~h}$ after seeding with Lipofectamine RNAiMAX reagent (Invitrogen, Carlsbad, CA, USA) at a final concentration of $30 \mathrm{nmol} / 1$, according to the manufacturer's protocol.

Proliferation assays. Transfected cells were seeded at a density of 2.5-3.0x $10^{4}$ per well in 24-well dishes. After cultured for 24, 48 and $72 \mathrm{~h}$, cells were trypsinized and stained with trypan blue solution (Invitrogen). The total number of cells in each well was determined with Countess Automated Cell Counter (Invitrogen).

Colony formation assay. Transfected cells were seeded at a density of 500 per well in 6-well plates. After incubation at $37^{\circ} \mathrm{C}$ for 10 days, cells were washed with PBS, fixed with formalin and stained with Giemsa solution. The number of visible colonies was counted with ImageJ software (National Institutes of Health).

Invasion assay. To measure cell invasion, transwell inserts with $8-\mu \mathrm{m}$ pores (BD Biosciences, San Jose, CA, USA) were used according to the manufacturer's protocol. The invading cells were fixed and stained with Diff-Quik (Sysmex, Hyogo, Japan), and counted under a light microscope in three random fields (x40 magnification).
Quantitative real-time polymerase chain reaction ( $q R T-P C R)$. Total RNA was isolated using miRNeasy Mini kit (Qiagen, Hilden, Germany) for clinical tissues and TRIzol reagent (Invitrogen) for cell lines following the manufacturer's protocol. RNA concentration and purity were assessed with NanoDrop ND-1000 spectrophotometer (NanoDrop Technologies, Rockland, DE, USA).

For miRNA quantification, TaqMan microRNA assays (Applied Biosystems, Foster City, CA, USA) were used: hsa-miR-487b ID 001285, and RNU6B ID 001093. Total RNA was reverse transcribed using TaqMan MicroRNA Reverse Transcription kit (Applied Biosystems). qRT-PCR was performed with ABI PRISM 7900HT Sequence Detection system (Applied Biosystems) using TaqMan Universal PCR Master Mix, No AmpErase UNG (Applied Biosystems). Relative expression was quantified with the $\Delta \Delta \mathrm{Cq}$ method (20).

For mRNA quantification, total RNA was reverse transcribed using High Capacity RNA-to-cDNA kit (Applied Biosystems). To measure KRAS expression level, qRT-PCR was performed with LightCycler 480 Real-Time PCR system (Roche Diagnostics, Mannheim, Germany) using the specific primers and LightCycler-DNA Master SYBR Green I (Roche Diagnostics) (21). The specifically designed primers were as follows: ACTB forward,5'-GATGAGATTGGCATGGCTTT-3'; reverse, 5'-CACCTTCACCGTTCCAGTTT-3'. KRAS forward, 5'-ATTCCTTTTATTGAAACATCAGCA-3'; reverse 5'-TCGG ATCTCCCTCACCAAT-3'. For LRP6 expression analysis, qRT-PCR was performed with ABI PRISM 7900HT Sequence Detection system (Applied Biosystems) using TaqMan Gene Expression Assays (Applied Biosystems) and TaqMan Universal PCR Master Mix, No AmpErase UNG (Applied Biosystems). The product numbers of TaqMan Gene Expression assay were as follows: ACTB ID Hs99999903_m1, LRP6 ID Hs00999795_m1. Relative expression was quantified using the $\Delta \Delta \mathrm{Cq}$ method (20).

Western blot analysis. Western blot analysis was performed as described previously (22). Briefly, cells were collected and lysed in RIPA buffer, containing phosphatase inhibitor and protease inhibitor cocktail. The protein lysates $(20 \mu \mathrm{g})$ from each sample were separated with sodium dodecyl sulfate-polyacrylamide gel electrophoresis (SDS-PAGE), and transferred electronically to a polyvinylidene difluoride membrane. The membrane was blocked with $5 \%$ skimmed milk and incubated with anti-human polyclonal antibodies against ERK, phosphorylated ERK, phosphorylated LRP6 (Cell Signaling Technology, Beverly, MA, USA), ACTB (Sigma-Aldrich), and anti-human monoclonal antibodies against AKT1, phosphorylated AKT, cleaved PARP, LRP6 (Cell Signaling Technology), KRAS (Sigma-Aldrich). The membrane was incubated with secondary antibodies, and visualized with the ECL Detection system (GE Healthcare, Little Chalfont, UK).

Luciferase reporter assay. For serum response element (SRE) luciferase reporter assay, the vector (pGL4.33[luc2P/SRE/ Hygro]) was obtained from Promega (Madison, WI, USA). For pmirGLO luciferase reporter assay, the vector was made as follows. The 3'-UTR of human LRP6 mRNA containing the putative miR-487b binding site was amplified by polymerase 
Table I. Patient chracteristics.

\begin{tabular}{|c|c|c|c|}
\hline $\begin{array}{l}\text { Patient } \\
\text { characteristics }\end{array}$ & $\begin{array}{c}\text { Without } \\
\text { metastasis } \\
\text { (stage I/II/III) }\end{array}$ & $\begin{array}{c}\text { With } \\
\text { liver } \\
\text { metastasis }\end{array}$ & $\begin{array}{c}\text { Liver } \\
\text { metastasis } \\
\text { lesion }\end{array}$ \\
\hline No. of patients & $96(18 / 38 / 40)$ & 22 & 16 \\
\hline \multicolumn{4}{|l|}{ Tumor size } \\
\hline$\leq 35 \mathrm{~mm}$ & 21 & 6 & \\
\hline$>35 \mathrm{~mm}$ & 75 & 16 & \\
\hline \multicolumn{4}{|l|}{ Location } \\
\hline Colon & 53 & 12 & \\
\hline Rectum & 43 & 10 & \\
\hline \multicolumn{4}{|l|}{ Differentiation } \\
\hline tub1, tub2 & 91 & 21 & \\
\hline muc, por & 5 & 1 & \\
\hline \multicolumn{4}{|l|}{ Depth } \\
\hline $\mathrm{T} 1, \mathrm{~T} 2$ & 20 & 0 & \\
\hline $\mathrm{T} 3, \mathrm{~T} 4$ & 76 & 22 & \\
\hline \multicolumn{4}{|l|}{$\begin{array}{l}\text { Lymph node } \\
\text { metastasis }\end{array}$} \\
\hline Negative & 56 & 5 & \\
\hline Positive & 40 & 17 & \\
\hline \multicolumn{4}{|c|}{ Lymphatic invasion } \\
\hline Negative & 51 & 4 & \\
\hline Positive & 45 & 18 & \\
\hline \multicolumn{4}{|l|}{ Venous invasion } \\
\hline Negative & 40 & 2 & \\
\hline Positive & 56 & 20 & \\
\hline
\end{tabular}

chain reaction (PCR). The primer sequences were; forward, 5'-GCTCGCTAGCCTCGAAGCAGGATGGGCGATAGA-3'; reverse 5'-ATGCCTGCAGGTCGATGGACAAGGGCTGAC CAA-3'. The amplified DNA product was cloned into the restriction site downstream of the firefly luciferase gene in pmirGLO vector (Promega). The vector with mutant 3'-UTR sequence was constructed using the QuikChange Site-Directed Mutagenesis kit (Agilent Technologies, Santa Clara, CA, USA) according to the manufacturer's protocol.

Cells were seeded in 96-well plates and transfected with both reporter vector and miRNA using Lipofectamine 2000 (Invitrogen), and collected $48 \mathrm{~h}$ after co-transfection. Luciferase activity was measured using Dual Luciferase Reporter assay system (Promega), as described previously $(16,23)$. Briefly, the cell extracts were prepared by rinsing each plate twice with PBS and lysing the cells in Passive Lysis buffer (Promega). The transfection efficiency was evaluated with renilla luciferase activity, and firefly luciferase activity was normalized.

Statistical analysis. The data are expressed as the mean \pm standard deviation. Statistical differences were analyzed by the Student's t-test for continuous variables and by the
Table II. The result of microarray analysis (fold change $>2.0$, $\mathrm{P}<0.05)$.

\begin{tabular}{rlll}
\hline 1 & hsa-miR-1 & 20 & hsa-miR-28-3p \\
2 & hsa-miR-10b & 21 & hsa-miR-3132 \\
3 & hsa-miR-1273e & 22 & hsa-miR-3154 \\
4 & hsa-miR-1288 & 23 & hsa-miR-3202 \\
5 & hsa-miR-132 & 24 & hsa-miR-337-5p \\
6 & hsa-miR-133a & 25 & hsa-miR-363 \\
7 & hsa-miR-133b & 26 & hsa-miR-381 \\
8 & hsa-miR-139-3p & 27 & hsa-miR-3917 \\
9 & hsa-miR-142-5p & 28 & hsa-miR-409-3p \\
10 & hsa-miR-143-3p & 29 & hsa-miR-4261 \\
11 & hsa-miR-143-5p & 30 & hsa-miR-4324 \\
12 & hsa-miR-145-5p & 31 & hsa-miR-4328 \\
13 & hsa-miR-145-3p & 32 & hsa-miR-450a \\
14 & hsa-miR-146a & 33 & hsa-miR-487b \\
15 & hsa-miR-152 & 34 & hsa-miR-493-5p \\
16 & hsa-miR-199a-3p & 35 & hsa-miR-495 \\
17 & hsa-miR-199b-5p & 36 & hsa-miR-582-5p \\
18 & hsa-miR-212 & 37 & hsa-miR-601 \\
19 & hsa-miR-223 & 38 & hsa-miR-625 \\
\hline
\end{tabular}

Chi-square test for the others. Survival curves were drawn by the Kaplan-Meier method, and compared using the log-rank test. The Cox proportional hazard regression model was used to estimate the hazard ratio (HR) and the $95 \%$ confidence interval (CI). All statistical analyses were conducted with JMP ver. 11.0.0 (SAS Institute, Inc., Cary, NC, USA). P-values of $<0.05$ were considered to be statistically significant.

\section{Results}

Identification of microRNAs with altered expression between colorectal and hepatic tissues by the microarray data. As a testing cohort, we used microarray data that were previously registered in the NCBI Gene Expression Omnibus database available through GEO with accession number GSE72199, consisting of tumor tissues derived from 36 patients: 16 primary CRC tumors with stage II and III disease without metastasis, 12 primary CRC tumors with simultaneous liver metastasis (stage IV), and 8 liver metastatic lesions of CRC (16). Consequently, 38 miRNAs that showed significantly differential expression with fold change $>2.0$ in microarray analyses were identified by comparison between primary tumors without metastasis and liver metastatic lesions (Table II). Among them, we found that the expression of miR-487b, which is reportedly shown as an anti-oncomir in several human malignancies (17-19), significantly decreased in liver metastatic lesions as compared to primary tumors without metastasis $(\mathrm{P}=0.030$, Fig. $1 \mathrm{~A})$. $\mathrm{qRT}$-PCR validated the result in the same testing cohort $(n=36, P=0.001$, Fig. $1 B)$. To confirm the statistical correlation between the results of microarray and qRT-PCR, Spearman's rank order correlation 

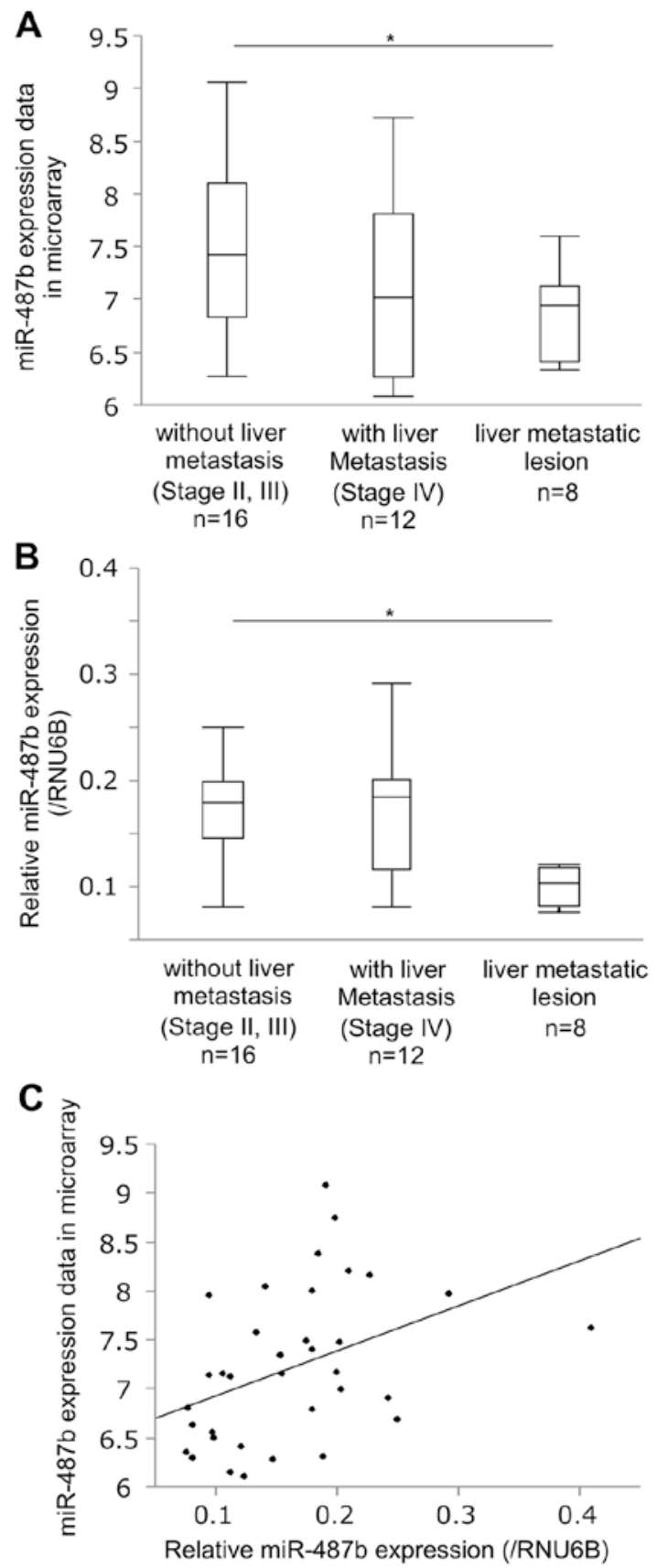

Figure 1. miR-487b expression in colorectal and hepatic tissues. (A) The result of microarray showed that miR-487b expression in liver metastatic lesions was lower than that in primary tumors without metastasis $(\mathrm{P}=0.030)$. (B) qRT-PCR was performed to validate the result of microarray data, and it demonstrated that miR-487b expression in liver metastatic lesions was significantly lower than that in primary CRC tumors without liver metastasis $(\mathrm{P}=0.001)$. (C) A significant correlation was observed between the results of microarray data and qRT-PCR $(\varrho=0.487, \mathrm{P}=0.003) .{ }^{*} \mathrm{P}<0.05$.

coefficient was calculated, which showed a significant correlation ( $\mathrm{Q}=0.487, \mathrm{P}=0.003$, Fig. 1C).

miR-487b is downregulated in CRC liver metastasis. To confirm the differential expression of miR-487b between primary tumors without metastasis, and liver metastatic lesions, miR-487b expression was measured by qRT-PCR in the validating cohort of 134 patients: primary tumors without metastasis $(n=96)$, primary tumors with liver metastasis $(\mathrm{n}=22)$, and liver metastatic lesions $(\mathrm{n}=16)$. It was confirmed that miR-487b expression in liver metastatic lesion was significantly lower than that in primary tumors without metastasis $(\mathrm{P}=0.041$, Fig. 2A). In addition, we found that miR-487b expression significantly decreased in primary tumors with liver metastasis, as compared to that without metastasis ( $\mathrm{P}=0.049$, Fig. 2A). When we examined miR-487b expression in a pair of CRC tissue and its corresponding synchronous liver metastasis $(n=7)$, metastatic lesions tended to express lower levels of miR-487b than the primary tumors $(\mathrm{P}=0.0996$, Fig. 2B). miR-487b expression in tumor tissues was significantly higher than that in their pair-matched adjacent normal mucosal tissues ( $\mathrm{P}=0.007$, Fig. $2 \mathrm{C})$.

Impact of miR-487b expression on the patient outcome. To reveal the impact of miR-487b expression on patient prognosis, 72 CRC patients were divided into two groups according to the median value of the miR-487b expression. Kaplan-Meier survival curve showed that the patients with high expression of miR-487b $(n=36)$ demonstrated better prognosis for overall survival $(\mathrm{OS})$ than those with low miR-487b expression $(\mathrm{n}=36$, $\mathrm{P}=0.036$, median follow-up 56.4 months, Fig. 2D). Univariate analysis showed that tumor depth $(\mathrm{P}<0.0001)$, tumor differentiation $(\mathrm{P}=0.040)$, lymph node metastasis $(\mathrm{P}=0.010)$, lymphatic invasion $(P=0.002)$, clinical stage $(P<0.0001)$, and miR-487b expression $(\mathrm{P}<0.032)$ were significant prognostic parameters (Table III). Multivariate analysis revealed that miR-487b expression was an independent prognostic factor for 5-year OS, (RR of 4.164, 95\% CI of 0.035), in addition to clinical stage (Table III). Clinical and pathological survey showed that miR-487b expression was significantly associated with tumor differentiation $(\mathrm{P}=0.040$, Table IV).

miR-487b inhibits cell proliferation and invasion ability in CRC cells. We then performed in vitro experiments using human CRC cell lines. First, qRT-PCR revealed that the miR-487b levels of representative four CRC cell lines were low compared to clinical normal tissue samples (Fig. 3A). The ectopic expression of miR-487b resulted in reduction of cell viability at 48 and $72 \mathrm{~h}$ after transfection in HCT116, and at $72 \mathrm{~h}$ in DLD-1 (Fig. 3B). Increased expression of miR-487b was validated at $48 \mathrm{~h}$ by qRT-PCR in both cell lines (Fig. 3C). In colony formation assay, the numbers of colonies significantly decreased in miR-487b transfected cells as compared to negative control cultures in both cell lines (Fig. 3D). We then assessed cell invasion, since it is thought to play a crucial role at an initial step of metastasis. miR-487b transduced cells showed a marked reduction in the invasion ability in both cell lines (Fig. 3E). These results indicate that miR-487b suppresses cell proliferation, and more evidently inhibits invasion ability in CRC.

miR-487b downregulates KRAS signaling pathway in CRC cells. To reveal the underlying mechanisms of how miR-487b would suppress proliferation and invasion ability, we explored KRAS signaling pathway because there is evidence that miR-487b targets 3'-UTRs of KRAS mRNA in lung cancer cell lines (17) (Fig. 4A). At $48 \mathrm{~h}$ after transfection, KRAS mRNA levels in miR-487b transfected cells significantly decreased compared with negative control cultures of HCT116 

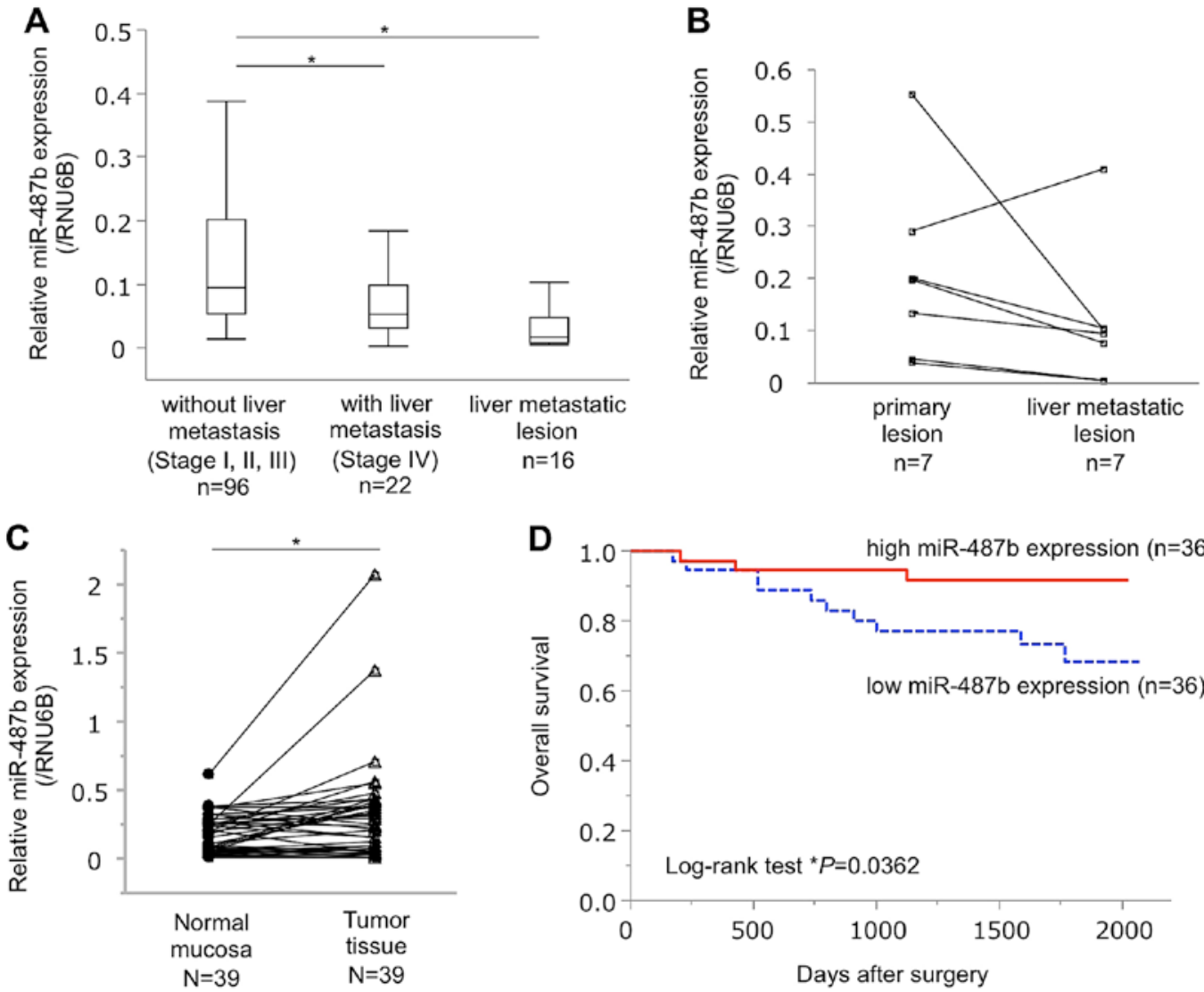

Figure 2. miR-487b expression in the independent cohort and survival analysis in patients with CRC. (A) In the validating cohort of 134 patients, miR-487b expression was lower in both liver metastatic lesions and primary tumors with liver metastasis, as compared to that without metastasis ( $\mathrm{P}=0.041$ and 0.049 , respectively). (B) miR-487b expression in seven pairs of primary tumors and corresponding synchronous liver metastatic lesions was analyzed by qRT-PCR. Metastatic lesions tended to express lower levels of miR-487b than primary tumors $(\mathrm{P}=0.0996)$. (C) miR-487b expression in tumor tissues ( $\mathrm{n}=39$ ) was higher than that in their pair-matched adjacent normal mucosal tissues ( $\mathrm{P}=0.007)$. (D) Kaplan-Meier survival curve showed that the patients with high expression of miR-487b $(n=36)$ demonstrated better prognosis for overall survival (OS) than those with low miR-487b expression $(\mathrm{n}=36$, $\mathrm{P}=0.036$, median follow-up 56.4 months). ${ }^{*} \mathrm{P}<0.05$.

Table III. Univariate and multivariate analyses for 5-year overall survival.

\begin{tabular}{|c|c|c|c|c|c|c|}
\hline & \multicolumn{2}{|c|}{ Univariate analysis } & \multirow[b]{2}{*}{ P-value } & \multicolumn{2}{|c|}{ Multivariate analysis } & \multirow[b]{2}{*}{ P-value } \\
\hline & $\mathrm{RR}$ & $95 \% \mathrm{CI}$ & & $\mathrm{RR}$ & $95 \% \mathrm{CI}$ & \\
\hline Gender (male/female) & 1.069 & $0.356-3.545$ & 0.906 & & & \\
\hline Tumor size $(\leq 35 \mathrm{~mm} />35 \mathrm{~mm})$ & 0.745 & $0.167-2.438$ & 0.647 & & & \\
\hline Location (colon/rectum) & 0.757 & $0.244-2.279$ & 0.616 & & & \\
\hline Differentiation (tub1, tub2/muc, por) & 0.569 & $0.112-10.383$ & 0.617 & & & \\
\hline Depth (T1-3/T4) & 0.075 & $0.012-0.282$ & $<0.0001^{\mathrm{a}}$ & 0.316 & $0.045-1.363$ & 0.131 \\
\hline Lymph node metastasis $(-/+)$ & 0.184 & $0.028-0.688$ & $0.010^{\mathrm{a}}$ & 0.319 & $0.047-1.311$ & 0.120 \\
\hline Lymphatic invasion $(-/+)$ & 0.09 & $0.005-0.459$ & $0.002^{\mathrm{a}}$ & 0.193 & $0.010-1.214$ & 0.085 \\
\hline Venous invasion $(-/+)$ & 0.262 & $0.014-1.331$ & 0.120 & 0.890 & $0.196-2.999$ & 0.860 \\
\hline Stage (I-III/IV) & 0.025 & $0.001-0.126$ & $<0.0001^{\mathrm{a}}$ & 0.099 & $0.005-0.714$ & $0.020^{\mathrm{a}}$ \\
\hline miR-487b expression (low/high) & 3.628 & $1.109-16.185$ & $0.032^{\mathrm{a}}$ & 4.164 & $1.097-21.600$ & $0.035^{\mathrm{a}}$ \\
\hline
\end{tabular}

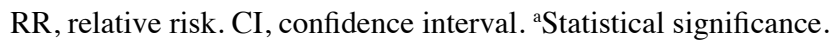

and DLD-1 cells (Fig. 4B), which was clearly demonstrated with western blot analysis at a protein level (Fig. 4C). Additional studies were undertaken to examine the impact of
miR-487b on downstream molecules of the KRAS signaling pathway. Phosphorylation of ERK and AKT in the miR-487b transfected cells decreased when compared to negative control 

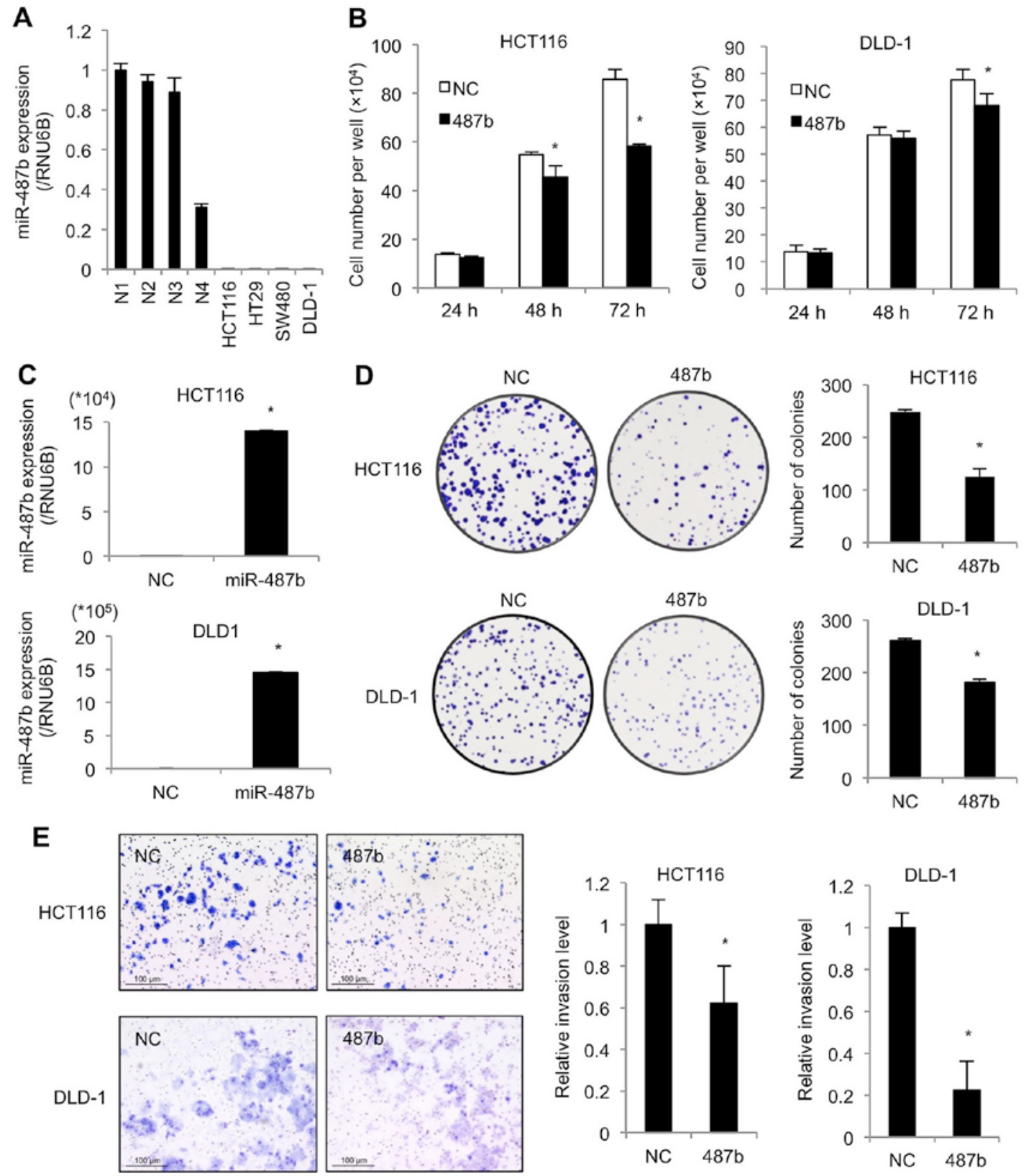

Figure 3. The overexpression of miR-487b inhibits cell proliferation and invasion in CRC cells. (A) qRT-PCR revealed that the miR-487b levels of representative four CRC cell lines (HCT116, HT29, SW480, and DLD-1) were low compared to clinical normal tissue samples. (B) The ectopic expression of miR-487b reduced cell viability at 48 and $72 \mathrm{~h}$ after transfection in HCT116, and at $72 \mathrm{~h}$ in DLD-1. (C) Increased expression of miR-487b was validated at $48 \mathrm{~h}$ by qRT-PCR in both cell lines. (D) Colony forming ability significantly decreased in miR-487b transfected cells as compared to negative control cultures in both cell lines. Left panels show the representative image of microscopic observation of 6-well plates. (E) miR-487b transduced cells showed a marked reduction in the invasion ability in both cell lines. Left panels show the representative image of microscopic observation. Scale bars, $100 \mu \mathrm{m}$. Data are presented as mean \pm SD from three different replicates. NC, negative control-transfected cells; 487b, miR-487b transfected cells. ${ }^{*}<<0.05$.

cultures (Fig. 4D). SRE reporter assay revealed that miR-487b significantly inhibited SRE luciferase activities, indicating that the MAPK/ERK signaling pathway was partially blocked by miR-487b (Fig. 4E). Since miR-487b could also regulate AKT signaling pathways, we next investigated whether miR-487b would induce apoptosis. We found that introduction of miR-487b increased cleaved PARP expression in HCT116 cells (Fig. 4F), but not in DLD-1 cells (data not shown).

miR-487b directly targets LRP6 in CRC cells. By using the target prediction tool (TargetScan 7.0, and microRNA.org.), we found that miR-487b might bind to the 3'-UTR of LRP6, a Frizzled (FZD) co-receptor for WNT signaling pathway (Figs. 5A and 6). After miR-487b was co-transfected with a reporter plasmid harboring LRP6 3'-UTR sequence, luciferase activities of the reporter were significantly reduced in HCT116 and DLD-1 cell lines (Fig. 5B), whereas, such decrease was not observed with mutant LRP6 3'-UTR sequence, indicating that LRP6 could be a direct target of miR-487b. At $48 \mathrm{~h}$ after transfection, LRP6 levels significantly decreased in both cell lines at mRNA and protein levels by treatment of miR-487b (Fig. 5C and D). Moreover, 


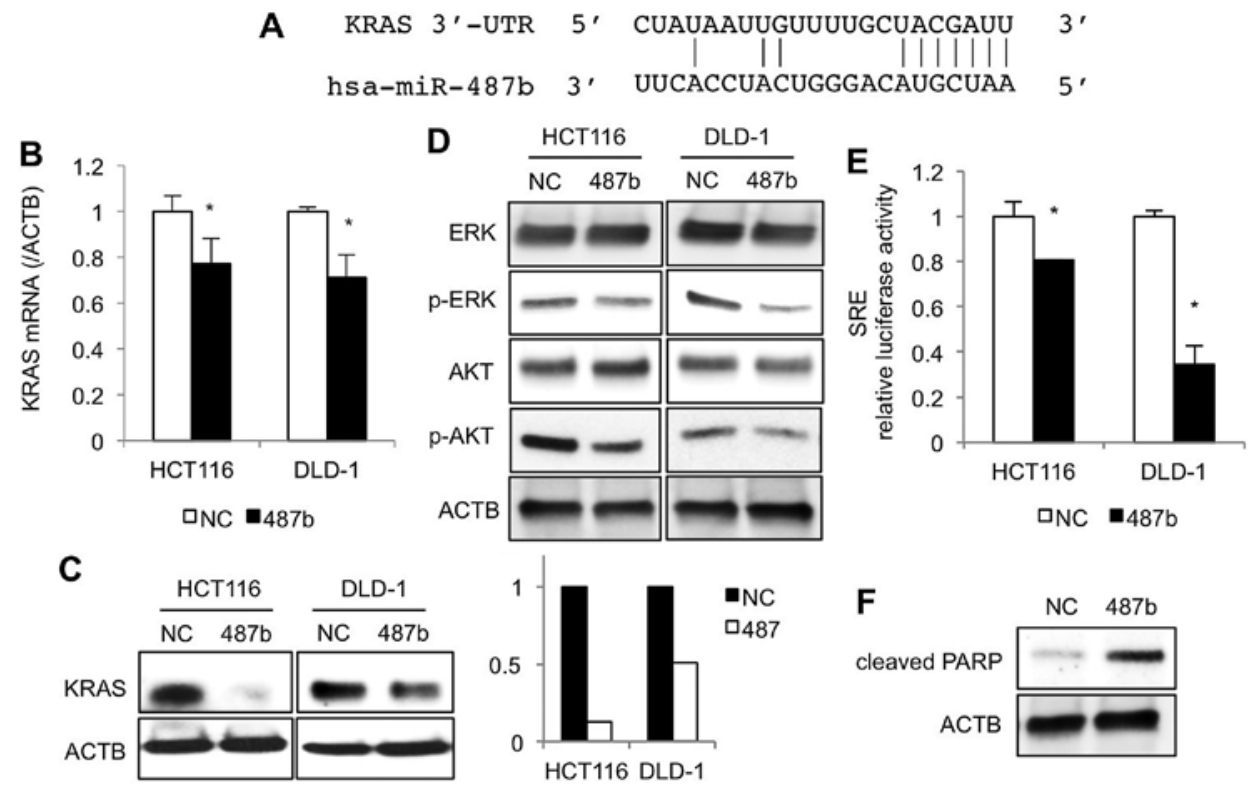

Figure 4. miR-487b inhibits KRAS expression and its downstream signaling, inducing apoptosis. (A) The 3'-UTR of KRAS contains putative binding site of miR-487b. (B) KRAS mRNA levels in miR-487b transfected cells significantly decreased compared with negative control cultures of HCT116 and DLD-1 cells. (C) Western blot analysis demonstrated that KRAS expression was downregulated in DLD-1 and HCT116 cells transfected with miR-487b at a protein level. Right panel shows the quantitative graphs of densitometry for the bands measured by ImageJ software. (D) Phosphorylation of ERK and AKT in the miR-487b transfected cells decreased when compared to negative control cultures. (E) SRE luciferase activities were significantly repressed by the introduction of miR-487b in both cell lines. (F) Cleaved PARP expression was upregulated in HCT116 cells treated with miR-487b. ACTB is a loading control in western blotting. Data are presented as mean \pm SD from three different replicates. NC, negative control-transfected cells; $487 \mathrm{~b}$, miR- $487 \mathrm{~b}$ transfected cells. "P $<0.05$.
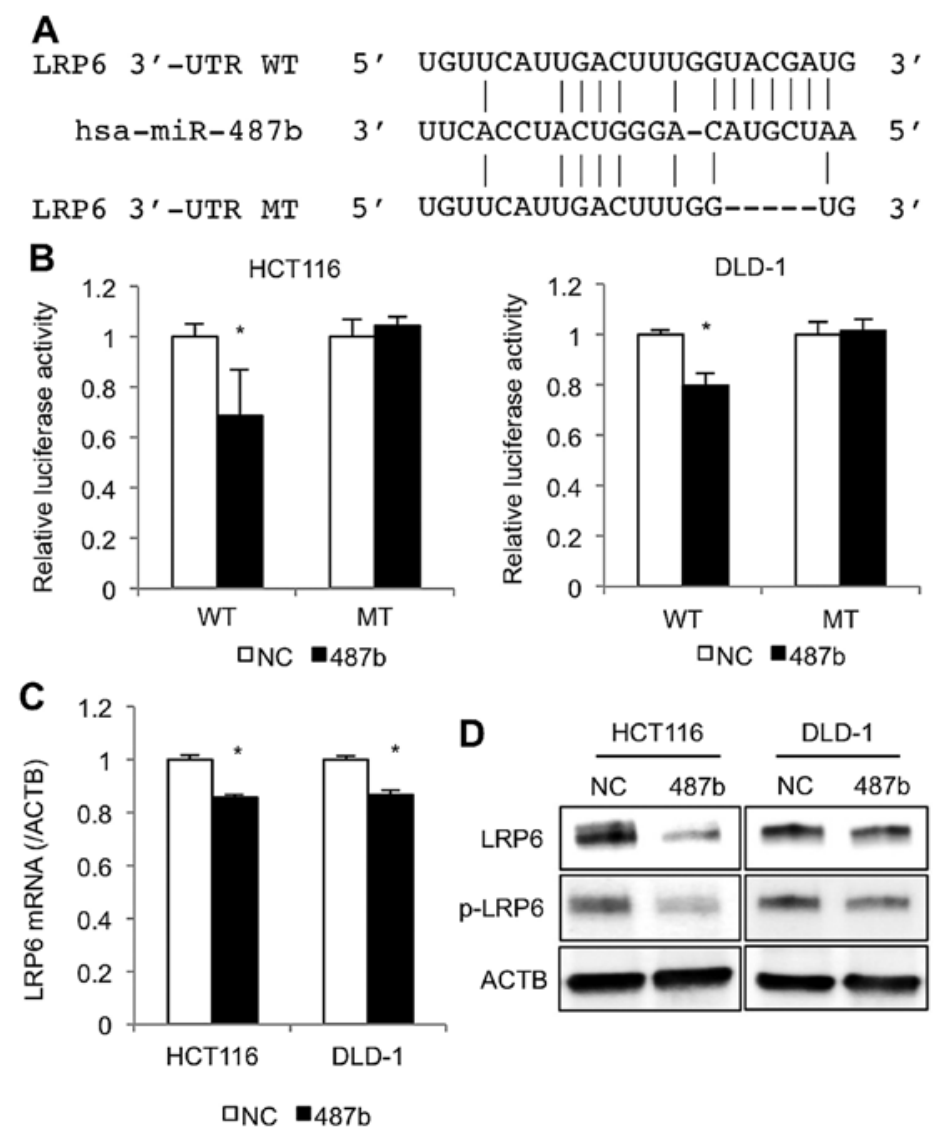

Figure 5. miR-487b inhibits the expression and phosphorylation of LRP6. (A) The 3'-UTR of LRP6 contains putative binding site of miR-487b. (B) Luciferase activities of the reporter plasmid containing wild LRP6 3'-UTR sequence (WT) were significantly repressed by the co-transfection of miR-487b, but not with mutant LRP6 3'-UTR sequence (MT). (C) LRP6 mRNA levels significantly decreased by ectopic expression of miR-487b. (D) Western blot analysis showed that both the expression and phosphorylation of LRP6 were reduced in miR-487b transfected cells as compared to negative control cultures in both cell lines. ACTB is a loading control. Data are presented as mean \pm SD from three different replicates. NC, negative control transfected cells; $487 \mathrm{~b}$, miR- $487 \mathrm{~b}$ transfected cells. ${ }^{*} \mathrm{P}<0.05$. 
Table IV. miR-487b expression and clinicopathological characteristics in colorectal cancer patients.

\begin{tabular}{|c|c|c|c|}
\hline $\begin{array}{l}\text { Patient } \\
\text { characteristics }\end{array}$ & $\begin{array}{l}\text { High miR-487b } \\
\text { expression } \\
(n=36)\end{array}$ & $\begin{array}{c}\text { Low miR-487b } \\
\text { expression } \\
(\mathrm{n}=36)\end{array}$ & P-value \\
\hline \multicolumn{4}{|l|}{ Gender } \\
\hline Male & 21 & 23 & \\
\hline Female & 15 & 13 & 0.629 \\
\hline \multicolumn{4}{|l|}{ Tumor size } \\
\hline$\leq 35 \mathrm{~mm}$ & 10 & 10 & \\
\hline$>35 \mathrm{~mm}$ & 26 & 26 & 1 \\
\hline \multicolumn{4}{|l|}{ Location } \\
\hline Colon & 16 & 21 & \\
\hline Rectum & 20 & 15 & 0.238 \\
\hline \multicolumn{4}{|l|}{ Differentiation } \\
\hline tub1, tub2 & 36 & 32 & \\
\hline muc, por & 0 & 4 & $0.040^{\mathrm{a}}$ \\
\hline \multicolumn{4}{|l|}{ Depth } \\
\hline $\mathrm{T} 1, \mathrm{~T} 2, \mathrm{~T} 3$ & 27 & 20 & \\
\hline $\mathrm{T} 4$ & 9 & 16 & 0.083 \\
\hline \multicolumn{4}{|l|}{$\begin{array}{l}\text { Lymph node } \\
\text { metastasis }\end{array}$} \\
\hline Negative & 14 & 18 & \\
\hline Positive & 22 & 18 & 0.343 \\
\hline \multicolumn{4}{|l|}{ Lymphatic } \\
\hline \multicolumn{4}{|l|}{ invasion } \\
\hline Negative & 13 & 18 & \\
\hline Positive & 23 & 18 & 0.234 \\
\hline \multicolumn{4}{|c|}{ Venous invasion } \\
\hline Negative & 6 & 11 & \\
\hline Positive & 30 & 25 & 0.165 \\
\hline \multicolumn{4}{|l|}{ Stage } \\
\hline I, II, III & 29 & 22 & \\
\hline IV & 7 & 14 & 0.07 \\
\hline
\end{tabular}

${ }^{a}$ Statistical significance.

transfection of miR-487b reduced the phosphorylated LRP6 protein (Fig. 5D), which was thought to be crucial for signal transduction in the WNT pathway.

\section{Discussion}

Studies have shown that miRNA-181a and miRNA-214 have the potential to suppress liver metastasis through targeting WNT inhibitory factor 1 (WIF-1) and fibroblast growth factor receptor 1 (FGFR1), respectively $(24,25)$. Our group also reported that miRNA-132 was related to liver metastasis of CRC and targets anoctamin 1 (ANO1) (16). In an effort
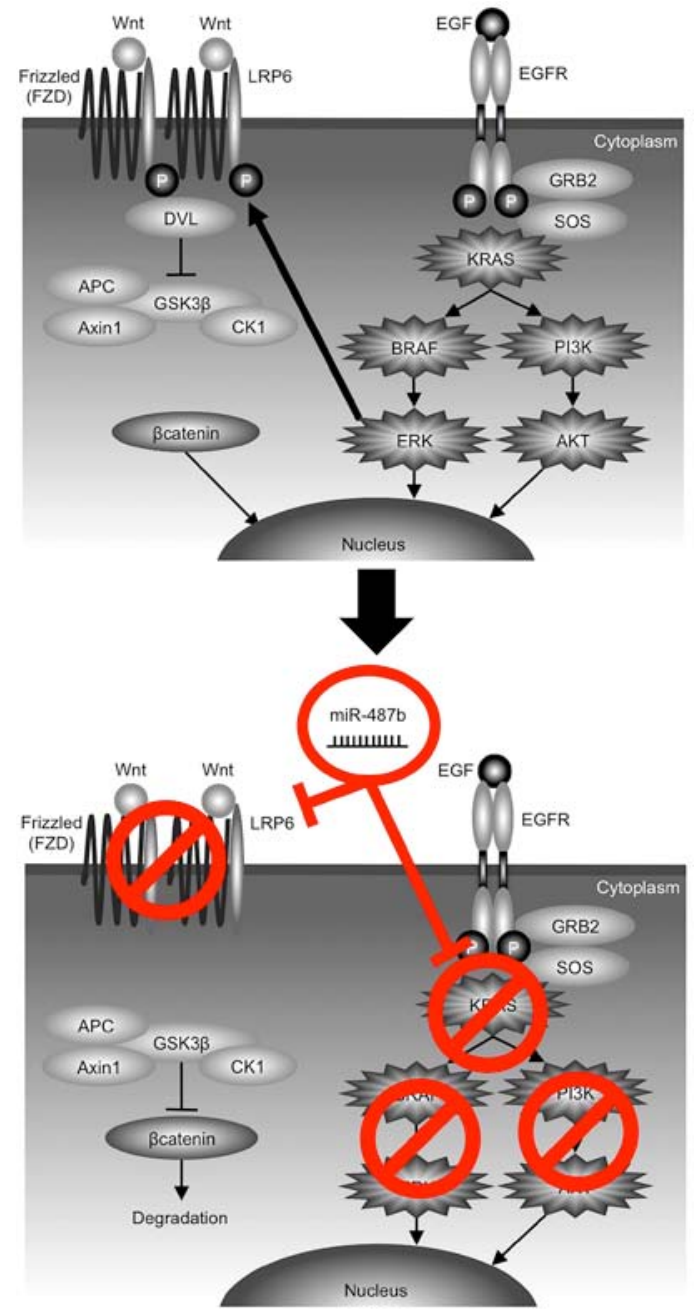

Figure 6. Schematic model of miR-487b, inhibiting MAPK/ERK, AKT, and ligand-dependent WNT/ $\beta$-catenin pathways. Exogenous miR-487b can suppress MAPK/ERK and AKT signaling through the downregulation of KRAS. miR-487b also targets LRP6, which forms a transmembrane receptor complex with Frizzled in presence of WNT ligand. In addition, ERK could facilitate WNT/ $\beta$-catenin signaling via LRP6 phosphorylation. Note that miR-487b should break the synergistic interaction between ERK and LRP6, as a result of the concurrent dual targeting of KRAS and LRP6.

to identify another novel miRNA related to liver metastasis, we focused on miR-487b that significantly decreased in liver metastatic lesions as compared to primary tumors without metastasis. In this study, we found that miR-487b level in tumors was even higher than that in their paired normal tissues. Since miR-487b acts as a tumor suppressor, this result seems to be somewhat contradictory. However, such paradox could happen in the process of carcinogenesis. Weinstein emphasized the existence of feedback mechanisms to maintain the homeostatic balance in human malignancies between positive and negative regulators of the cell cycle, by showing that CDK inhibitors $\mathrm{p} 21^{\mathrm{Cip} 1 / \text { Waf } 1}$, $\mathrm{p} 27^{\mathrm{Kip} 1}$, or even $R b$ tumor suppressor gene products increased in several cancer types $(26,27)$. Similar scenario is reported in case of miRNA. Thus, anti-onco miR-132 or -133b rather increased in tumor tissues (28-30). In addition, some reports showed that miR-34a, a representative anti-oncomir $(31,32)$, was shown to be upregulated in cancer tissue rather than in normal mucosa $(30,33)$. Therefore, we postulate that the present findings of an increase 
in miR-487b in tumor tissues may not be unique considering the complex miRNA networks in cancer development.

Our study revealed that miR-487b inhibited cell proliferation, colony formation, and cell invasion. These findings suggest that miR-487b may play a role as an anti-oncomir (i.e., tumor suppressor) as demonstrated by other studies; Xi et al reported that miR-487b targets SUZ12, BMI1, WNT5A, MYC and KRAS and that its expression was downregulated in lung cancer (17). Gattolliat et al showed that high miR-487b expression was a marker for improved prognosis in neuroblastoma (19). In this study, we focused on RAS and WNT/ $\beta$-catenin signaling pathway, both of which are essential for cancer metastasis $(34,35)$.

Consistent with a previous study by Xi et al (17), we confirmed that miR-487b clearly downregulated KRAS expression in CRC, which linked to decrease in phosphorylation of ERK and AKT. miR-487b eventually decreased the SRE transcription activity. Earlier studies have established the roles of KRAS-dependent signaling in enhancement of cell proliferation, invasion and metastasis in CRC $(34,36)$. The mutation status of KRAS gene is one of the most essential factors for treatment strategy against CRC in the use of antiEGFR antibody. Moreover, recent studies have shown that the emergence of KRAS mutations is a mediator of acquired resistance to EGFR blockade $(37,38)$. In this regard, the ability of miR-487b to suppress MAPK/ERK and AKT signaling might be an effective approach to CRC with KRAS mutation.

LRP6, a single span transmembrane protein, is a crucial component of the WNT/ $\beta$-catenin signaling pathway. We found that LRP6 harbored miR-487b binding sequence in its 3'-UTR by miRNA target screening and validated this binding. LRP6 forms a receptor complex with FZD in presence of WNT ligand, and DVL recruitment by FZD leads to LRP6 phosphorylation and Axin recruitment, which allows $\beta$-catenin to accumulate in the nucleus where it serves as a coactivator for TCF to activate WNT-responsive genes (39) (Fig. 6). LRP6 has been shown to function as an oncogene by promoting cell growth, invasion and migration, and is expected to be a target for cancer therapy (40-45). Notably, there is evidence that ERK1/2 in the RAS/MAPK pathway could facilitate WNT/ $\beta$-catenin signaling via LRP6 phosphorylation on serine-1490 (S1490) and threonine-1572 (T1572) at both mature (transmenbrane LRP6) and immature state during its Golgi network-based maturation process $(46,47)$. Taken together, it is conceivable that miR-487b may further contribute to break the synergistic interaction between ERK and LRP6, as a result of the concurrent dual targeting of KRAS and LRP6 (Fig. 6). Downstream of LRP6, however, it is known that a majority of CRC harbors mutation in $A P C$ or $C T N N B 1$ gene and the frequency of gene mutations involved in the canonical WNT/ $\beta$-catenin pathway accounted for more than $90 \%$ (48-51). Therefore, it should be carefully assessed to what extent downregulation of LRP6 would affect the WNT/ $\beta$-catenin signaling and the malignant potential of CRC. Further investigation on this issue is essential as the next step.

In conclusion, this study demonstrated that decreased expression of miR-487b was associated with liver metastasis and that miR-487b may play a crucial role in regulating tumor progression in CRC through targeting KRAS. Our data suggest that miR-487b could be a sensitive marker for liver metastasis and prognosis of the patients. Further study is needed to establish a novel strategy using miR-487b for treatment against $\mathrm{CRC}$.

\section{Acknowledgements}

This study was supported by a Grant-in Aid for Scientific Research (KAKENHI) to Hirofumi Yamamoto (nos. 21390360, 30322184 and 24390315).

\section{References}

1. Torre LA, Bray F, Siegel RL, Ferlay J, Lortet-Tieulent J and Jemal A: Global cancer statistics, 2012. CA Cancer J Clin 65: 87-108, 2015.

2. Brenner H, Kloor M and Pox CP: Colorectal cancer. Lancet 383: 1490-1502, 2014

3. Kopetz S, Chang GJ, Overman MJ, Eng C, Sargent DJ,Larson DW, Grothey A, Vauthey JN, Nagorney DM and McWilliams RR: Improved survival in metastatic colorectal cancer is associated with adoption of hepatic resection and improved chemotherapy. J Clin Oncol 27: 3677-3683, 2009.

4. Leonard GD, Brenner B and Kemeny NE: Neoadjuvant chemotherapy before liver resection for patients with unresectable liver metastases from colorectal carcinoma. J Clin Oncol 23: 2038-2048, 2005.

5. Amano R, Yamada N, Nakata B, Kimura K, Yashiro M, Ohira M and Hirakawa K: Prognostic indicator for the resection of liver metastasis of colorectal cancer. Surg Today 44: 1287-1292, 2014

6. Sorski L, Levi B, Shaashua L, Neeman E, Benish M, Matzner P, Hoffman A and Ben-Eliyahu S: Impact of surgical extent and sex on the hepatic metastasis of colon cancer. Surg Today 44: 1925-1934, 2014.

7. Chen $\mathrm{K}$ and Rajewsky N: The evolution of gene regulation by transcription factors and microRNAs. Nat Rev Genet 8: 93-103, 2007.

8. He L and Hannon GJ: MicroRNAs: Small RNAs with a big role in gene regulation. Nat Rev Genet 5: 522-531, 2004.

9. Zhang $\mathrm{H}, \mathrm{Li}$ Y and Lai M: The microRNA network and tumor metastasis. Oncogene 29: 937-948, 2010.

10. Lu J, Getz G, Miska EA, Alvarez-Saavedra E, Lamb J, Peck D, Sweet-Cordero A, Ebert BL, Mak RH, Ferrando AA, et al: MicroRNA expression profiles classify human cancers. Nature 435: 834-838, 2005.

11. Kent OA and Mendell JT: A small piece in the cancer puzzle: MicroRNAs as tumor suppressors and oncogenes. Oncogene 25: 6188-6196, 2006.

12. Chen CZ: MicroRNAs as oncogenes and tumor suppressors. N Engl J Med 353: 1768-1771, 2005.

13. Stiegelbauer V, Perakis S, Deutsch A, Ling H, Gerger A and Pichler M: MicroRNAs as novel predictive biomarkers and therapeutic targets in colorectal cancer. World J Gastroenterol 20: 11727-11735, 2014

14. Wu WK, Law PT, Lee CW, Cho CH, Fan D, Wu K, Yu J and Sung JJ: MicroRNA in colorectal cancer: From benchtop to bedside. Carcinogenesis 32: 247-253, 2011.

15. US National Institutes of Health: A multicenter phase I study of MRX34, microRNA miR-RX34 liposomal injection. https:// clinicaltrials.gov/ct2/show/NCT01829971. Accessed May 27, 2016.

16. Mokutani Y, Uemura M, Munakata K, Okuzaki D, Haraguchi N, Takahashi H, Nishimura J, Hata T, Murata K, Takemasa I, et al: Down-regulation of microRNA-132 is associated with poor prognosis of colorectal cancer. Ann Surg Oncol: Feb 11, 2016 (Epub ahead of print).

17. Xi S, Xu H, Shan J, Tao Y, Hong JA, Inchauste S, Zhang M, Kunst TF, Mercedes L and Schrump DS: Cigarette smoke mediates epigenetic repression of miR-487b during pulmonary carcinogenesis. J Clin Invest 123: 1241-1261, 2013.

18. Stewart DJ: Wnt signaling pathway in non-small cell lung cancer. J Natl Cancer Inst 106: djt356, 2014.

19. Gattolliat CH, Thomas L, Ciafrè SA, Meurice G, Le Teuff G, Job B, Richon C, Combaret V, Dessen P, Valteau-Couanet D, et al: Expression of miR-487b and miR-410 encoded by $14 \mathrm{q} 32.31$ locus is a prognostic marker in neuroblastoma. Br J Cancer 105: 1352-1361, 2011 
20. Livak KJ and Schmittgen TD: Analysis of relative gene expression data using real-time quantitative PCR and the 2(-Delta Delta $\mathrm{C}(\mathrm{T})$ ) method. Methods 25: 402-408, 2001.

21. Yamamoto H, Murata K, Fukunaga M, Ohnishi T, Noura S Miyake Y, Kato T, Ohtsuka M, Nakamura Y, Takemasa I, et al: Micrometastasis volume in lymph nodes determines disease recurrence rate of stage II colorectal cancer: A prospective multicenter trial. Clin Cancer Res 22: 3201-3208, 2016

22. Hamabe A, Konno M, Tanuma N, Shima H, Tsunekuni K, Kawamoto K, Nishida N, Koseki J, Mimori K, Gotoh N, et al: Role of pyruvate kinase M2 in transcriptional regulation leading to epithelial-mesenchymal transition. Proc Natl Acad Sci USA 111: 15526-15531, 2014

23. Hiraki M, Nishimura J, Takahashi H, Wu X, Takahashi Y, Miyo M, Nishida N, Uemura M, Hata T, Takemasa I, et al: Concurrent targeting of KRAS and AKT by miR-4689 is a novel treatment against mutant KRAS colorectal cancer. Mol Ther Nucleic Acids 4: e231, 2015.

24. Ji D, Chen Z, Li M, Zhan T, Yao Y, Zhang Z, Xi J, Yan L and Gu J: MicroRNA-181a promotes tumor growth and liver metastasis in colorectal cancer by targeting the tumor suppressor WIF-1. Mol Cancer 13: 86, 2014

25. Chen DL, Wang ZQ, Zeng ZL, Wu WJ, Zhang DS, Luo HY, Wang F, Qiu MZ, Wang DS, Ren C, et al: Identification of microRNA-214 as a negative regulator of colorectal cancer liver metastasis by way of regulation of fibroblast growth factor receptor 1 expression. Hepatology 60: 598-609, 2014.

26. Weinstein IB: Disorders in cell circuitry during multistage carcinogenesis: The role of homeostasis. Carcinogenesis 21: 857-864, 2000.

27. Weinstein IB, Begemann M, Zhou P, Han EK, Sgambato A, Doki Y, Arber N, Ciaparrone M and Yamamoto H: Disorders in cell circuitry associated with multistage carcinogenesis: Exploitable targets for cancer prevention and therapy. Clin Cancer Res 3: 2696-2702, 1997.

28. Zheng YB, Luo HP, Shi Q, Hao ZN, Ding Y, Wang QS, Li SB Xiao GC and Tong SL: miR-132 inhibits colorectal cancer invasion and metastasis via directly targeting ZEB2. World J Gastroenterol 20: 6515-6522, 2014.

29. Lin CW, Li XR, Zhang Y, Hu G, Guo YH, Zhou JY, Du J, Lv L, Gao K, Zhang Y, et al: TAp63 suppress metastasis via miR-133b in colon cancer cells. Br J Cancer 110: 2310-2320, 2014.

30. Kara M, Yumrutas O, Ozcan O, Celik OI, Bozgeyik E, Bozgeyik I and Tasdemir S: Differential expressions of cancer-associated genes and their regulatory miRNAs in colorectal carcinoma. Gene 567: 81-86, 2015.

31. Gao J, Li N, Dong Y, Li S, Xu L, Li X, Li Y, Li Z, Ng SS, Sung JJ, et al: $\mathrm{miR}-34 \mathrm{a}-5 \mathrm{p}$ suppresses colorectal cancer metastasis and predicts recurrence in patients with stage II/III colorectal cancer. Oncogene 34: 4142-4152, 2015.

32. Raver-Shapira N, Marciano E, Meiri E, Spector Y, Rosenfeld N, Moskovits N, Bentwich Z and Oren M: Transcriptional activation of miR-34a contributes to p53-mediated apoptosis. Mol Cell 26: 731-743, 2007

33. Krell J, Frampton AE, Mirnezami R, Harding V, De Giorgio A Roca Alonso L, Cohen P, Ottaviani S, Colombo T, Jacob J, et al: Growth arrest-specific transcript 5 associated snoRNA levels are related to p53 expression and DNA damage in colorectal cancer. PLoS One 9: e98561, 2014.

34. Smakman N, Borel Rinkes IH, Voest EE and Kranenburg O: Control of colorectal metastasis formation by K-Ras. Biochim Biophys Acta 1756: 103-114, 2005.
35. Anastas JN and Moon RT: WNT signalling pathways as therapeutic targets in cancer. Nat Rev Cancer 13: 11-26, 2013

36. Pretlow TP and Pretlow TG: Mutant KRAS in aberrant crypt foci (ACF): Initiation of colorectal cancer? Biochim Biophys Acta 1756: 83-96, 2005.

37. Misale S, Yaeger R, Hobor S, Scala E, Janakiraman M, Liska D, Valtorta E, Schiavo R, Buscarino M, Siravegna G, et al: Emergence of KRAS mutations and acquired resistance to anti-EGFR therapy in colorectal cancer. Nature 486: 532-536, 2012.

38. Diaz LA Jr, Williams RT, Wu J, Kinde I, Hecht JR, Berlin J, Allen B, Bozic I, Reiter JG, Nowak MA, et al: The molecular evolution of acquired resistance to targeted EGFR blockade in colorectal cancers. Nature 486: 537-540, 2012.

39. MacDonald BT, Tamai K and He X: Wnt/beta-catenin signaling: Components, mechanisms, and diseases. Dev Cell 17: 9-26, 2009.

40. Li Y, Lu W, He X, Schwartz AL and Bu G: LRP6 expression promotes cancer cell proliferation and tumorigenesis by altering beta-catenin subcellular distribution. Oncogene 23: 9129-9135, 2004.

41. Liu CC, Prior J, Piwnica-Worms D and Bu G: LRP6 overexpression defines a class of breast cancer subtype and is a target for therapy. Proc Natl Acad Sci USA 107: 5136-5141, 2010.

42. Tung EK, Wong BY, Yau TO and Ng IO: Upregulation of the Wnt co-receptor LRP6 promotes hepatocarcinogenesis and enhances cell invasion. PLoS One 7: e36565, 2012.

43. Du C, Lv Z, Cao L, Ding C, Gyabaah OA, Xie H, Zhou L, Wu J and Zheng S: MiR-126-3p suppresses tumor metastasis and angiogenesis of hepatocellular carcinoma by targeting LRP6 and PIK3R2. J Transl Med 12: 259, 2014

44. Zhang Y, Zheng D, Xiong Y, Xue C, Chen G, Yan B and Ye Q miR-202 suppresses cell proliferation in human hepatocellular carcinoma by downregulating LRP6 post-transcriptionally. FEBS Lett 588: 1913-1920, 2014

45. Zeng XC, Liu FQ, Yan R, Yi HM, Zhang T, Wang GY, Li Y and Jiang N: Downregulation of miR-610 promotes proliferation and tumorigenicity and activates Wnt//-catenin signaling in human hepatocellular carcinoma. Mol Cancer 13: 261, 2014

46. Lemieux E, Cagnol S, Beaudry K, Carrier J and Rivard N: Oncogenic KRAS signalling promotes the Wnt/ $\beta$-catenin pathway through LRP6 in colorectal cancer. Oncogene 34: 4914-4927, 2015.

47. Krejci P, Aklian A, Kaucka M, Sevcikova E, Prochazkova J, Masek JK, Mikolka P, Pospisilova T, Spoustova T, Weis M, et al: Receptor tyrosine kinases activate canonical WNT/ $\beta$-catenin signaling via MAP kinase/LRP6 pathway and direct $\beta$-catenin phosphorylation. PLoS One 7: e35826, 2012.

48. Morin PJ, Sparks AB, Korinek V, Barker N, Clevers H, Vogelstein B and Kinzler KW: Activation of beta-catenin-Tcf signaling in colon cancer by mutations in beta-catenin or APC. Science 275: 1787-1790, 1997.

49. Bienz $M$ and Clevers $H$ : Linking colorectal cancer to Wnt signaling. Cell 103: 311-320, 2000.

50. Cancer Genome Atlas N; Cancer Genome Atlas Network: Comprehensive molecular characterization of human colon and rectal cancer. Nature 487: 330-337, 2012.

51. Masuda M, Uno Y, Ohbayashi N, Ohata H, Mimata A, KukimotoNiino M, Moriyama $\mathrm{H}$, Kashimoto $\mathrm{S}$, Inoue $\mathrm{T}$, Goto $\mathrm{N}$, et al: TNIK inhibition abrogates colorectal cancer stemness. Nat Commun 7: 12586, 2016. 